\title{
Comparison of serum cystatin $C$ and creatinine based methods in detection of early renal dysfunction in critically Ill patients
}

\author{
Mohammed H. Hafez ${ }^{1}$; Yasser M. Abdelhamid ${ }^{1}$ and Asmaa I. Ahmed ${ }^{2}$ \\ Division of Nephrology - Department of Internal Medicine ${ }^{1}$; Department of Chemical Pathology ${ }^{2}$, Faculty of Medicine, \\ Cairo University, Cairo, Egypt.
}

\begin{abstract}
Early detection of renal dysfunction is of importance in the care of critically ill patients. Cystatin $\mathrm{C}$ was proposed to be superior to serum creatinine in estimation of renal function. This work aimed to compare serum cystatin $\mathrm{C}$ to serum creatinine and creatinine based formulae in detection of early decline in renal function at a single point in critically ill patients. Fifty critically ill patients admitted to Cairo University Hospitals ICUs - Egyptwere included. Patients with chronic renal disease, thyroid disease, malignancy, patients receiving corticosteroid therapy, with serum creatinine $>1.4 \mathrm{mg} / \mathrm{dl}$ and patients receiving diuretics or large volumes of IV fluids were excluded. Serum creatinine, serum cystatin $\mathrm{C}$, adjusted creatinine clearance (Adj Ccr), estimated GFR (eGFR) by modification of diet in renal disease (MDRD), abbreviated MDRD (abb MDRD) and Cockcroft-Gault (CG) formulae were measured. Patients with renal dysfunction (adj Ccr $<80 \mathrm{ml} / \mathrm{min} / 1.73 \mathrm{~m}^{2}$ ) were $26(52 \%)$ in number. Patients with renal dysfunction and high serum creatinine were $12 / 26$ (46.2\%) while those with high cystatin C were 23/26 (88.5\%). Cystatin $\mathrm{C}$ was found to be significantly correlated with serum creatinine, adj Ccr and eGFR by all studied formulae. Using receiver operating characteristic (ROC) analysis; AUC for Cystatin C (0.976) was more than that for eGFR by abb MDRD (AUC $=0.839), \quad M D R D \quad(A U C=0.822), \quad C G$ formulae $(\mathrm{AUC}=0.808)$ and serum creatinine $(\mathrm{AUC}=0.710)$ respectively. In conclusion; cystatin $\mathrm{C}$ was found to be better than serum creatinine, eGFR by abb MDRD, MDRD and $C G$ formulae in detection of early renal dysfunction at a single point in critically ill patients.
\end{abstract}

Correspondence and offprint requests to: Dr. Yasser M. Abdelhamid, M.D. Lecturer of Nephrology, Faculty of Medicine - Cairo University - Egypt.

E-mail: dyabdelhamid@hotmail.com
Key words: Creatinine; critically ill; cystatin C; GFR MDRD.

\section{Introduction}

Assessment and follow up of renal function is an integral part of medical care of ICU patients. Serum creatinine level is affected by many other factors than renal function as muscle mass, gender, age, diet and tubular secretion [1]. In cases of acute kidney injury, there is no enough time for creatinine to accumulate in serum and for serum creatinine level to reflect the degree of renal dysfunction. So, the major benefit of serum creatinine appears to be mainly in stable patients [2]. Determination of GFR with high adequacy requires the use of specific techniques based on measuring clearance rate of an injected substance such as inulin or ${ }^{51} \mathrm{Cr}$-EDTA [3]. In order to avoid the use of invasive methods, several equations depending on serum creatinine and other variables have been developed for calculation of GFR [4]. Cystatin C is a member of cystatin superfamily of cystein protease inhibitors that had been proposed as a marker of GFR and was proposed to be superior to serum creatinine especially in cases of mild renal insufficiency $[5,6]$. Using the clearance of radioisothalamate as the gold standard, serum cystatin $\mathrm{C}$ began increasing at GFR level of $\sim 90 \mathrm{ml} / \mathrm{min} / 1.73 \mathrm{~m}^{2}$ while serum creatinine only increased when GFR was $\sim 70 \mathrm{ml} / \mathrm{min} / 1.73 \mathrm{~m}^{2}$ [7]. In the settings of acute kidney injury in critically ill patients, Cystatin $\mathrm{C}$ was found in some studies to be more sensitive and of superior diagnostic value in detection of mild decrease in GFR than serum creatinine while in others it was not found to have such a significance [811]. This study aimed to compare the ability of serum cystatin $\mathrm{C}$ to serum creatinine and creatinine based formulae in detection of early renal function decline at a single point in critically ill patients. 


\section{Material and methods}

The protocol of this study was first approved by the scientific board of Nephrology Division - Internal Medicine Department and Committee of Research Ethics; Faculty of Medicine - Cairo University - Egypt. Fifty patients were included who were admitted to different ICUs in Cairo University Hospitals. Informed consents were obtained either from the patient himself or a first degree relative in the case of patient inability. Clinical characteristics of patients are illustrated in table(1). Excluded patients were those with chronic renal disease, thyroid disease, malignancy and patients receiving corticosteroid therapy due to expectedly high serum cystatin C [12-14]. Patients with serum creatinine more than $1.4 \mathrm{mg} / \mathrm{dl}$ and patients receiving diuretics or large volumes of IV fluids were also excluded.

Urine collection was done over a 24 hour period using indwelling urinary catheter starting from 8:00 am to 8:00 am next day; the time at which a blood sample was taken for estimation of serum creatinine, blood urea nitrogen (BUN), serum albumin and serum cystatin C.

Measurement of serum cystatin $\mathrm{C}$ was done using RD191009100 human Cystatin C ELISA.

Adjusted creatinine clearance (Adj Ccr) was calculated using the following equation [3]:

Adj CCr $\left(\mathrm{ml} / \mathrm{min} / \mathrm{m}^{2}\right)=[(24$ hour urine volume $\mathrm{X}$ urine creatinine)/ (Serum creatinine $X$ 1440)] X 1.73/ calculated BSA.

Body surface area $(\mathrm{BSA})=\sqrt{ }[\mathrm{Ht}(\mathrm{cm}) \times \mathrm{Wt}(\mathrm{kg}) / 360]$ [15].

Glomerular filtration rate $(\mathrm{ml} / \mathrm{min})$ was estimated (eGFR) using the following equations:
Modification of diet in renal disease (MDRD) formula: $\mathrm{GFR}=170 \mathrm{X} \quad(\mathrm{s} . \mathrm{Cr})^{-0.999} \mathrm{X}$ age $^{-0.176} \mathrm{X} \mathrm{BUN}^{-0.17} \mathrm{X}$ S.Albumin ${ }^{+0.318}$ X 0.762 (if female).

Abbreviated MDRD (abb MDRD) formula [16]:

$\mathrm{GFR}=186 \times$ serum creatinine $(\mathrm{mg} / \mathrm{dl})^{-1.154} \mathrm{x}$ age $(\text { years })^{-}$ 0.203 X 0.742 for females.

Cockcroft-Gault (CG) formula [17]:

$(140$ - age $) \mathrm{x}$ lean body weight $[\mathrm{kg}] \mathrm{X}(0.85$ for females $)$

$\mathrm{GFR}=\frac{\mathrm{Cr}[\mathrm{mg} / \mathrm{dl}] \times 72}{\mathrm{c}}$

Adjusted creatinine clearance was used as a reference for GFR in our study. A level of $80 \mathrm{ml} / \mathrm{min} / 1.73 \mathrm{~m}^{2}$ was used as a cut off value for renal dysfunction $[4,7]$.

Statistical methods:

Data were statistically described in terms of range, mean \pm standard deviation (SD), median and 95\%CI of the mean. Categorical data were summarized as percentages. Pearson's correlation coefficient was used to measure the strength of association between two variables. Accuracy was represented using the terms sensitivity and specificity. Receiver operator characteristic (ROC) analysis was used to determine the optimum cut off value for the studied diagnostic markers. All P-values are two-sided. P-values $<0.05$ were considered significant. Data management and analysis were performed using Statistical Analysis Systems \{(Microsoft Excel 2003 (Microsoft Corporation, NY, USA) and Stats Direct statistical software version 2.7.2 for MS Windows, StatsDirect Ltd., Cheshire, UK)\}.

\section{Results}

Mean \pm SD of laboratory parameters of patients enrolled in our study are illustrated in table 1.

Table 1. Clinical and laboratory parameters of included patients.

\begin{tabular}{|c|c|}
\hline Variable & Description \\
\hline Age $($ mean \pm SD) & $51.9 \pm 13.9$ y $(15-86$ y) \\
\hline Sex (male/female) & $30 / 20(60 / 40 \%)$ \\
\hline \multicolumn{2}{|l|}{ Diagnosis (number \%): } \\
\hline Acute MI & $25 \mathrm{pt}(50 \%)$ \\
\hline Respiratory failure & $6 \mathrm{pt}(12 \%)$ \\
\hline Hepatic coma & $6 \mathrm{pt}(12 \%)$ \\
\hline Intracerebral hemorrhage & $2 \mathrm{pt}(4 \%)$ \\
\hline Status epilepticus & $1 \mathrm{pt}(2 \%)$ \\
\hline Post CABG & $1 \mathrm{pt}(2 \%)$ \\
\hline Sepsis & $1 \mathrm{pt}(2 \%)$ \\
\hline APACHE II score (mean \pm SD) & $14.23 \pm 6.77$ \\
\hline Serum creatinine $($ mean $\pm S D)(n=0.5-1.4 \mathrm{mg} / \mathrm{dl})$ & $1.102 \pm 0.283 \mathrm{mg} / \mathrm{dl}$ \\
\hline Serum cystatin $C($ mean $\pm S D)(n=620-1150 \mathrm{ng} / \mathrm{l})$ & $1175.8 \pm 702.2 \mathrm{ng} / 1$ \\
\hline Adjusted Creatinine clearance $($ mean $\pm \mathrm{SD})\left(\mathrm{ml} / \mathrm{min} / 1.73 \mathrm{~m}^{2}\right)($ mean $\pm \mathrm{SD})$ & $87.24 \pm 48.93 \mathrm{ml} / \mathrm{min} / 1.73 \mathrm{~m}^{2}$ \\
\hline eGFR by $\mathrm{CG}$ formula $(\mathrm{ml} / \mathrm{min})($ mean $\pm \mathrm{SD})$ & $87.46 \pm 39.58 \mathrm{ml} / \mathrm{min}$ \\
\hline eGFR by MDRD formula (ml/min) (mean \pm SD) & $65.2 \pm 31.72 \mathrm{ml} / \mathrm{min}$ \\
\hline eGFR by abb MDRD formula $(\mathrm{ml} / \mathrm{min})(\mathrm{mean} \pm \mathrm{SD})$ & $77.24 \pm 37.45 \mathrm{ml} / \mathrm{min}$ \\
\hline
\end{tabular}

Patients with adj $\mathrm{Ccr}>80 \mathrm{ml} / \mathrm{min} / 1.73 \mathrm{~m}^{2}$ were $24(48 \%)$ in number while patients with adj $\mathrm{Ccr}<80$ $\mathrm{ml} / \mathrm{min} / 1.73 \mathrm{~m}^{2}$ were $26(52 \%)$ in number. Among patients with low adj Ccr, number of patients with elevated level of serum cystatin $\mathrm{C}$ was found to be higher than number of patients with elevated serum creatinine. Regarding patients with adj Ccr $>80 \mathrm{ml} / \mathrm{min} / 1.73 \mathrm{~m}^{2}$; number of patients with elevated serum creatinine was found to be slightly higher than those with elevated serum cystatin C (figure 1). 


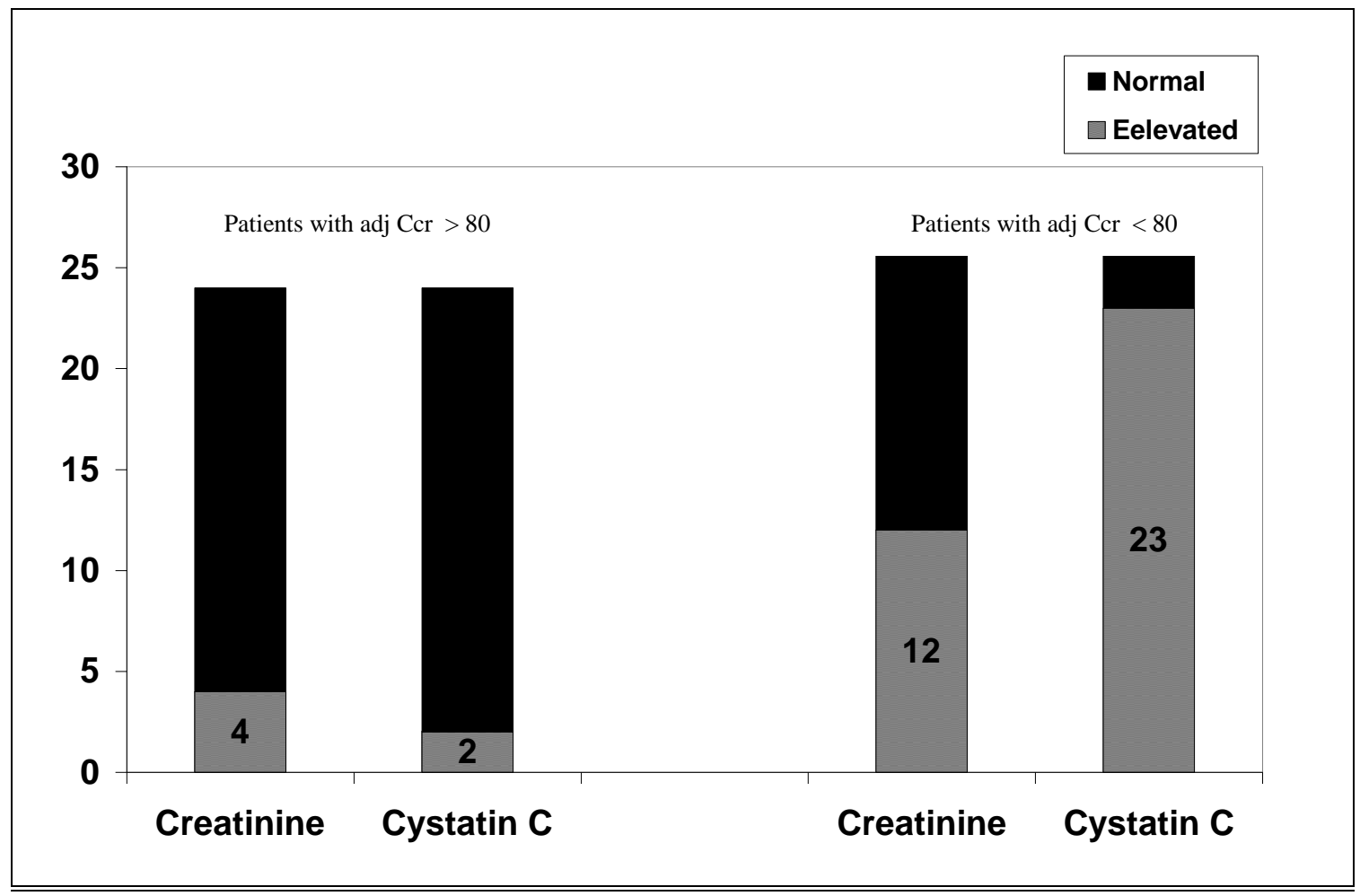

Fig. 1. Number of patients with normal and elevated serum creatinine and serum cystatin $\mathrm{C}$ levels in critically ill patients with renal dysfunction (adj Ccr < $80 \mathrm{ml} / \mathrm{min} / 1.73 \mathrm{~m}^{2}$, number $\left.=26\right)$ and in patients with adj $\mathrm{Ccr}>80 \mathrm{ml} / \mathrm{min} / 1.73 \mathrm{~m}^{2}($ number $=24)$.

Serum cystatin $\mathrm{C}$ was found to be significantly correlated with serum creatinine, adj Ccr and eGFR by all creatinine based formulae (figure 2). Similarly, adjusted creatinine clearance was found to have significant correlation with serum creatinine $(r=-0.604, p<0001)$ and creatinine based formulae ( $<<0001$ for all). Using receiver operating characteristic plots (ROC) for analysis of diagnostic values of both serum cystatin $\mathrm{C}$ and creatinine based methods; area under the curve (AUC) for cystatin $\mathrm{C}$ was found to be higher than that for serum creatinine and other creatinine based formulae indicating better diagnostic ability for serum cystatin $\mathrm{C}$ than other methods in detecting renal dysfunction at a cut off value of adjusted creatinine clearance of $80 \mathrm{ml} / \mathrm{min} / 1.73 \mathrm{~m}^{2}$ (table 2, figure 3).

Table 2. Receiver operating characteristic (ROC) analysis for serum cystatin $\mathrm{C}$ and other creatinine based methods in detection of renal dysfunction (adj $\mathrm{Ccr}<80 \mathrm{ml} / \mathrm{min} / 1.73 \mathrm{~m}^{2}$ ).

Cystatin C abb MDRD formula MDRD formula Serum creatinine CG formula

$\begin{array}{llllll}\text { AUC } & 0.976 & 0.839 & 0.822 & 0.808 & 0.710 \\ 95 \% \text { CI } & 0.938-1 & 0.436-1 & 0.437-1 & 0.629-0.925 & 0.430-0.991 \\ \text { Sensitivity } & 1 & 0.786 & 0.75 & 0.679 & 0.464 \\ 95 \% \text { CI } & 0.877-1 & 0.591-0.917 & 0.551-0.839 & 0.476-0.841 & 0.275-0.661 \\ \text { Specificity } & 0.864 & 0.864 & 0.864 & 0.772 & 0.955 \\ 95 \% \text { CI } & 0.651-0.971 & 0.651-0.971 & 0.651-0.971 & 0.546-0.921 & 0.772-0.999\end{array}$

(AUC: area under the curve, CI: confidence interval, MDRD: modification of diet in renal disease, Abb MDRD: abbreviated MDRD, CG: CockcroftGault). 

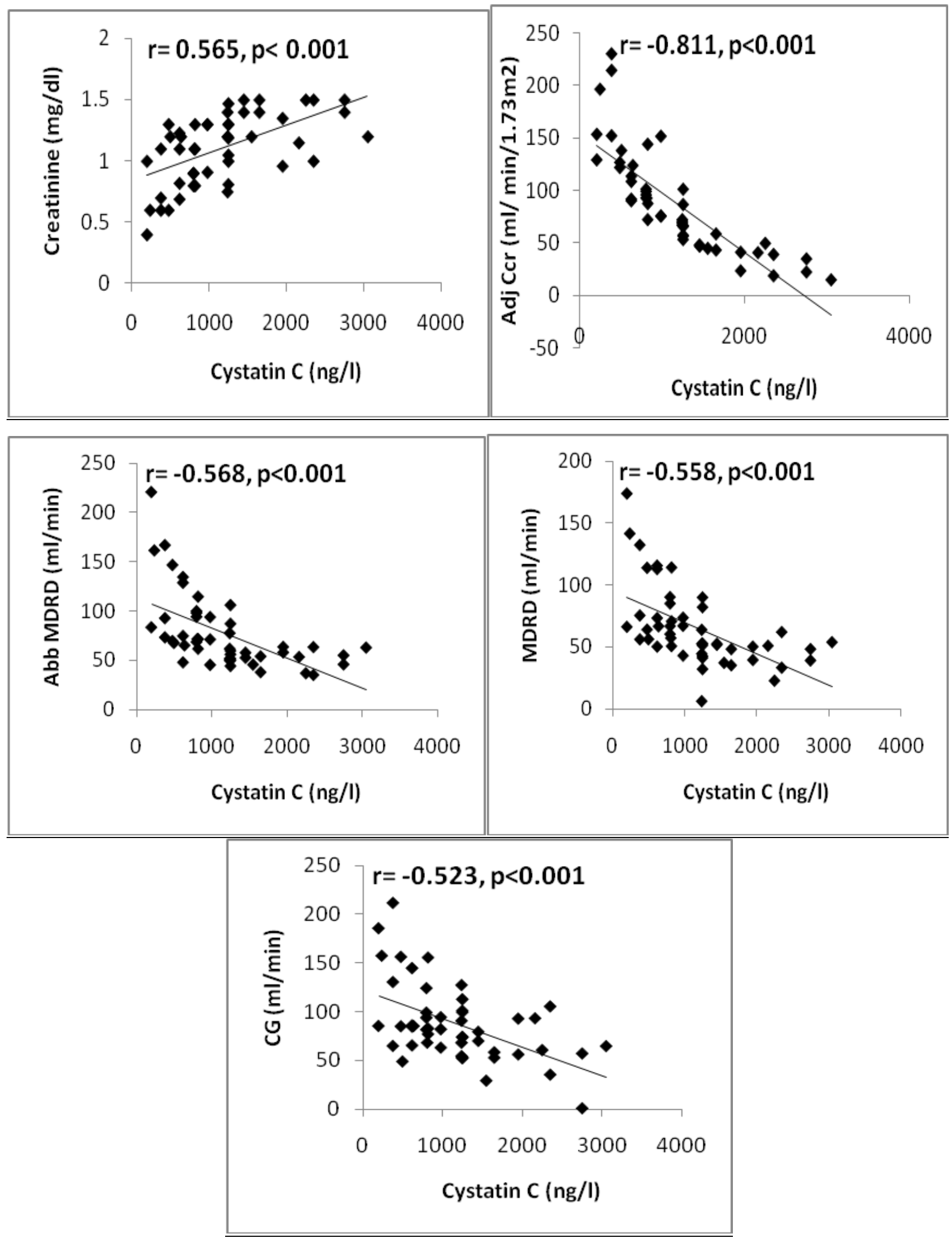

Fig. 2. Correlations of serum cystatin $\mathrm{C}$ to serum creatinine, adjusted creatinine clearance (adj Ccr), eGFR by modification of diet in renal disease (MDRD), abbreviated MDRD (abb MDRD) and cockcroft-gault (CG) formulae. 

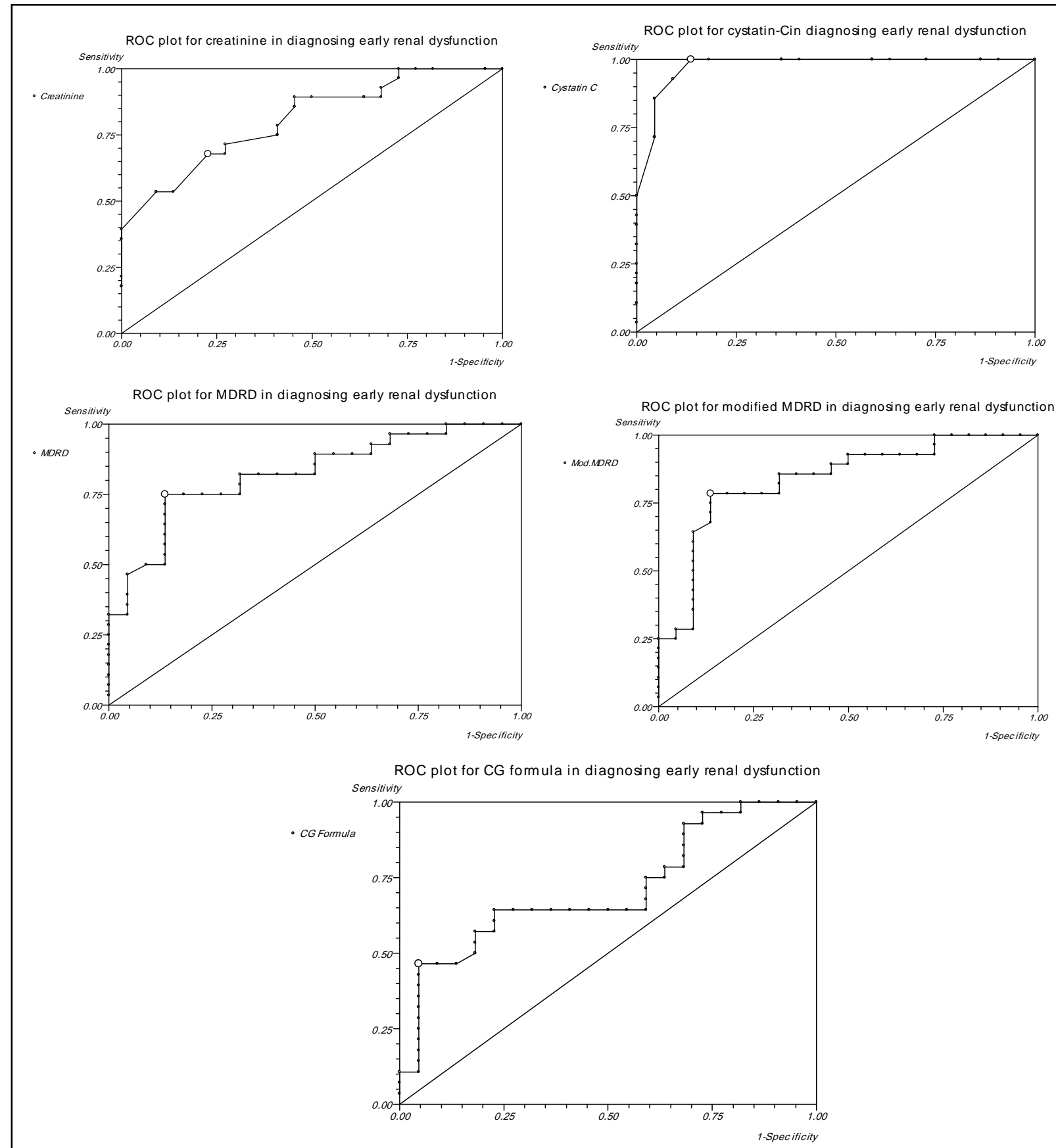

Fig. 3. Receiver operating characteristic plots (ROC curve) for sensitivity and specificity of serum cystatin C and creatinine based formulae in detecting early renal dysfunction (adj $\mathrm{Ccr}<80 \mathrm{ml} / \mathrm{min} / 1.73 \mathrm{~m}^{2}$ ). Area under the curve for serum cystatin $\mathrm{C}$ is higher than creatinine based methods. (MDRD: modification of diet in renal disease, $\mathrm{CG}$ : cockcroft-gault).

\section{Discussion}

Early detection of renal dysfunction is of extreme importance in directing management of critically ill patients. There are many limitations the use of serum creatinine for this purpose including delay of rise after considerable affection of GFR. Cystatin C production in the body is a stable process for which it was suggested to be an ideal endogenous marker representing GFR [18, 19].

In our study, area under the curve for serum cystatin C was found to be larger than that for serum creatinine. Also, number of patients with high serum cystatin $\mathrm{C}$ was higher than those with high serum creatinine among patients with renal dysfunction detected by adj Ccr. Thus, serum cystatin $\mathrm{C}$ was found to be better than 
serum creatinine in detection of renal dysfunction in critically ill patients at our used cut off value of adj Ccr. Moreover, cystatin $\mathrm{C}$ was found to be better correlated with adj Ccr than serum creatinine. The diagnostic utility of cystatin $\mathrm{C}$ seen in our study was close to what was previously reported by other investigators. In a study done by Villa and her associates, 50 critically ill patients were included. Their number of patients with renal dysfunction was nearly similar to us ( 25 vs 26 ). Our patients with renal dysfunction having a high level of serum cystatin $\mathrm{C}$ were higher than those of the study of Villa et al (23 vs 19). However, in their study and ours this was higher in number than patients with high serum creatinine. Similar to ours, higher AUC for serum cystatin $\mathrm{C}$ than for serum creatinine was found in critically ill patients [20-21]. Earlier rise of serum cystatin $\mathrm{C}$ than serum creatinine was found in patients developing renal dysfunction [22]. In a comment on the study of Villa et al, the use of adj Ccr as a control for GFR was disagreed and the use of more accurate methods for GFR detection as inulin and isothalamate clearances was advised. [23]. Most studies conducted to evaluate whether there is a role for serum cystatin $\mathrm{C}$ in determining GFR involved measurement of the clearance of an exogenous substances such as ${ }^{51} \mathrm{Cr}$-EDTA as the gold standard [24]. Nevertheless, creatinine clearance could be considered as a reliable marker for determining GFR on a routine basis, and multiple studies used creatinine clearance as a control for evaluating the role for serum cystatin $C$ as a measure of GFR $[21,25]$. In our study, we also used adjusted creatinine clearance as a reference for evaluating GFR inspite of its limitations due to its relative simplicity and convenience in critically ill patients. Urine collection was done using indwelling urinary catheter avoiding bias of urine collection and patients receiving large volumes of IV fluids or diuretic therapy were excluded.

In the current study serum cystatin $\mathrm{C}$ was found to be better than creatinine based formulae including CG formula, MDRD and abb MDRD formulae in detection of renal dysfunction. A cystatin $\mathrm{C}$ prediction equation was found to be equally sensitive or slightly better than MDRD formulae in predicting GFR in a large number of patients with variable diagnoses [26, 27]. In patients with native kidney disease; cystatin $C$ was found to be better correlated with GFR than MDRD and CG equations [28]. Similar to what was found in critically ill patients [29] and renal transplant recipients [30] we found that serum cystatin C was significantly correlated with serum creatinine, adj Ccr, GFR calculated by abb MDRD, MDRD, and with CG formulae.

In addition to the use of Adj Ccr as the gold standard for GFR, another limitation of the current study was the use of single assessment of renal functions both for cystatin $\mathrm{C}$ and creatinine based methods. Serial measurements of serum creatinine and cystatin $\mathrm{C}$ are better done to detect decline of renal functions in such dynamic unstable patients. Moreover, a more specific formula that takes into consideration fluctuations in serum creatinine such as Jelliffe equation, which can be adjusted to daily fluid balance, seems to be better for the study of changes in renal functions in unstable critically ill patients than CG or MDRD formulae [31].

Conclusion; serum cystatin $\mathrm{C}$ was found to be better than serum creatinine, eGFR by abb MDRD, MDRD and CG formulae in detection of early renal dysfunction at a single point in critically ill patients. Further studies are recommended to further clarify these points using a more specific gold standard for estimation of GFR than adjusted creatinine clearance and including a serial follow up of studied data with a larger number of patients.

Acknowledgment: To Dr. Hamdy. A. Abdel-Halim, Nephrology specialist; Student Hospital, To Intensive Care Unit - Internal Medicine Department and to Critical Care Department; Faculty of Medicine, Cairo University, Egypt.

\section{References}

1. Rule AD, Bergstralh EJ, Slezak JM et al.: Glomerular filtration rate estimated by cystatin $\mathrm{C}$ among different clinical presentations. Kidney Int. 2006; 69:399-405.

2. Perrone RD, Madias NE, Levey AS: Serum creatinine as an index of renal function: new insights into old concepts. Clin Chem. 1992; 38: 1933-53.

3. Levey AS: Measurement of renal function in chronic renal disease. Kidney Int. 1990; 38: 167-84.

4. Levey AS and Coresh J: K/DOQI clinical practice guidelines on chronic kidney disease. Guideline 4. Estimation of GFR. Am J Kidney Dis. 2002; 39 (Suppl 1): 76-92.

5. Dharnidharka, VR, Kwon C, Stevens, G: Serum cystatin C is superior to serum creatinine as a marker of kidney function: a meta analysis. Am J Kidney Dis. 2002; 40: 221- 6.

6. Knight EL, Verhave JC, Spiegelman D et al.: Factors influencing serum cystatin $\mathrm{C}$ levels other than renal function and the impact on renal function measurement. Kidney Int. 2004; 65: 1416-21.

7. Perkins BA, Nelson RG, Ostrander BE et al.: Detection of renal function decline in patients with diabetes and normal or elevated GFR by serial measurements of serum cystatin C Concentration: Results of a 4-year follow-up study. J Am Soc Nephrol. 2005; 16: 1404-12.

8. Royakkers AA, Van Suijlen JD, Hofstra LS et al.: Serum cystatin C-A useful endogenous marker of renal function in intensive care unit patients at risk for or with acute renal failure?. Curr Med Chem. 2007; 14 (21): 2314-7.

9. Herrero-Morín JD, Málaga S, Fernández $\mathrm{N}$ et al.: Cystatin $\mathrm{C}$ and beta2-microglobulin: Markers of glomerular filtration in critically ill children. Crit Care. 2007; 11(3): R59.

10. Herget-Rosenthal S, Marggraf G, Hüsing $J$ et al.: Early detection of acute renal failure by serum cystatin C. Kidney Int. 2004; 66(3):1115-22.

11. Mazul-Sunko B, Zarković N, Vrkić $\mathrm{N}$ et al.: Proatrial natriuretic peptide (1-98), but not cystatin C, is predictive for occurrence of acute renal insufficiency in critically ill septic patients. Nephron Clin Pract. 2004; 97(3): c103-7.

12. den Hollander JG, Wulkan RW, Mantel MJ et al.: Is cystatin C a marker of glomerular filtration rate in thyroid dysfunction? Clin Chem. 2003; 49 (9): 1558-9.

13. Kos J, Stabuc B, Cimerman $\mathrm{N}$ et al.: Serum cystatin C, a new marker of glomerular filtration rate, is increased during malignant progression. Clin Chem. 1998; 44 (12): 2556-7.

14. Westhuyzen J. Cystatin C: A promising marker and predictor of impaired renal function. Ann Clin Lab Sci. 2006; 36 (4): 387-94.

15. Mosteller, RD.: Simplified calculation of body surface area. N Engl J Med. 1987; $317: 1098$ (letter). 
16. Levey AS, Bosch JP, Lewis JB et al.: A more accurate method to estimate glomerular filtration rate from serum creatinine: A new prediction equation. Modification of Diet in Renal Disease Study Group. Ann Intern Med.1999; 130 (6): 461-70.

17. Cockcroft, DW and Gault MH.: Prediction of creatinine clearance from serum creatinine. Nephron. 1976; 16: 31-41.

18. Bostom AG, Kronenberg F, Ritz E.: Predictive performance of renal function equations for patients with chronic kidney disease and normal serum creatinine levels. J Am Soc Nephrol. 2002; 13: 2140-4.

19. Chew JS, Saleem M, Florkowski CM et al.: Cystatin C-a paradigm of evidence based laboratory medicine.Clin Biochem Rev. 2008; 29 (2): 47-62.

20. Hoek FJ, Kemperman FA, Krediet RT.: A comparison between cystatin C, plasma creatinine and the Cockcroft and Gault formula for the estimation of glomerular filtration rate. Nephrol Dial Transplan. 2003; 18(10): 2024-31.

21. Villa P, Jiménez M, Soriano MC et al.: Serum cystatin C concentration as a marker of acute renal dysfunction in critically ill patients. Critical Care. 2005; 9 (2): R139-43.

22. Mazur MJ and Heilman RL.: Early detection of acute renal failure by serum cystatin C: A new opportunity for a hepatologist. Liver Transpl. 2005; 11(6): 705-7.

23. Wulkan R, den Hollander J, Berghout A.: Cystatin C: Unsuited to use as a marker of kidney function in the intensive care unit. Critical Care. 2005; 9 (2): R139-43.

24. Newman DJ, Thakkar H, Edwards RG et al.: Serum cystatin C measured by automated inmunoassay: A more sensitive marker of changes in GFR than serum creatinine. Kidney Int. 1995; 47: 312-318.

25. Paskalev E, Lambreva L, Simeonov P et al.: Serum cystatin C in renal transplant patients. Clin Chim Acta. 2001; 310: 53-56.

26. Grubb A, Nyman U, Björk J et al.: Simple cystatin C-based prediction equations for glomerular filtration rate compared with the modification of diet in renal disease prediction equation for adults and the Schwartz and the Counahan-Barratt prediction equations for children. Clin Chem 2005; 51(8): 1420-31.

27. Sterner G, Björk $\mathbf{J}$, Carlson $\mathbf{J}$ et al.: Validation of a new plasma cystatin C-based formula and the Modification of Diet in Renal Disease creatinine-based formula for determination of glomerular filtration rate. Scand J Urol Nephro. 2009; 43 (3): 242-9.

28. Rule AD, Bergstralh EJ, Slezak JM et al.: Glomerular filtration rate estimated by cystatin $\mathrm{C}$ among different clinical presentations. Kidney Int. 2000; 69, 399-405.

29. Tarif N, Alwakeel JS, Mitwalli AH et al.: Serum cystatin C as a marker of renal function in patients with acute renal failure. Saudi J Kidney Dis Transp. 2008; 19 (6): 918-23.

30. Zahran A, Qureshi M, Shoker A.: Comparison between creatinine and cystatin C-based GFR equations in renal transplantation. Nephrol Dial Transplant. 2007; 22 (9): 265968.

31. Bouchard J, Macedo E, Soroko S et al.: Comparison of methods for estimating glomerular filtration rate in critically ill patients with acute kidney injury. Nephrol Dial Transplant. 2010; 25: $102-107$. 